G488(P) CHILD PROTECTION TRAINING: MEETING THE UNMET NEEDS

${ }^{1} S$ Saran, ${ }^{2} \mathrm{P}$ Sharma. ${ }^{1}$ Paediatrics, Shropshire Community Health NHS Trust, Shrewsbury, UKi ${ }^{2}$ Paediatrics, Epsom and St Helier University Hospitals NHS Trust, Epsom, UK

10.1136/archdischild-2020-rcpch.418

Background Suboptimal quality of child protection medical examination notes and reports, not only exposes the child, siblings (and at times Doctor) to an increased risk but also jeopardises the decision-making process of the court.

Aim To evaluate the effectiveness of hands-on training on child protection notes taking and report writing in a workshop setting.

Method A cross-sectional study (survey) was conducted amongst the participants to the workshop on child protection notes taking and report writing in the annual scientific meeting of British Association of Community Child Health (BACCH) in 2019.

Results A total of thirty-eight delegates attended the workshop. Twenty-five of them responded to the survey.

Participants: Forty-eight per cent were consultants, forty per cent were paediatric trainees, and twelve per cent were SAS doctors.

Previous Child protection experience: Forty-four per cent had an experience of fewer than 5 years, twenty-eight per cent between 5 to 10 years and twenty-eight per cent over 10 years. Improvement Reported: Over seventy per cent of the participants reported an improved understanding of Child Protection processes, related laws, legal jargons and role of the professional and expert witnesses.

Over eighty per cent stated feeling more confident in dealing with Child protection queries after attending the workshop and recommended attending the workshop to their fellow colleagues.

Over ninety per cent delegates testified an improvement in their ability to record notes and write good quality Child Protection medical report.

Conclusion There is a pressing need to address the quality of Child protection training across the country in-line with the $\mathrm{RCPCH}$ recommendations "Safeguarding children and young people: roles and competencies for paediatricians", August 2019.

The authors also recommends incorporating notes taking and report writing skills in the annual appraisal of the consultants undertaking Child Protection work.

\section{G489(P) A YEAR IN THE LIFE OF THE PAEDIATRIC SEXUAL ASSAULT SERVICE - PROVIDING A SERVICE FOR THE LOCAL POPULATION}

'L Shonfeld, 1,2F Straw. 'Department of Community Paediatrics, Nottingham University Hospitals, Nottingham, UK; ${ }^{2}$ East Midlands Children and Young Peoples Sexual Assualt Service, Nottingham, UK

\subsection{6/archdischild-2020-rcpch.419}

Background A medical examination may be considered in the Paediatric Sexual Assault Service when there is an allegation or suspicion of sexual abuse in a child or young person.

It is important to ensure a universally equitable service for all young people, including those with disabilities. Services delivering this must be high quality, readily accessible, open access services for all regardless of gender or sexual orientation.
Our local service has been operating for more than a year and aims to provide this high quality service.

Aims The aim of this project was to evaluate the data over a year to look at the age, sex/gender, ethnicity and address of each of the young people to ensure that the service is open to all, and to provide data to improve awareness and access to the service.

Methods We identified every child and young person who was examined in the service and collated data of their sex, ethnicity, age and any identified disabilities. Using post codes we mapped the use of the service across the region producing a pictorial representation of the use of the service.

Results There were 410 children and young people seen. 43 (10\%) Male, 364 (89\%) Female, 3 (1\%) Transgender. The largest number of examinations were carried out for older children $>13$ although there was a spread of examinations across all ages $0-18$.

The largest ethnic group was White British (261) followed by White-Other (29) and Black or British Black African (10).

$53(12 \%)$ had a physical or learning disability.

A map of the postcodes showed a spread across the region, with a predictable peak in each of the urban areas.

Conclusion The service provided care to children and young people of all ages and gender, across a wide spread of ethnicities and across the region. Females, teenagers and people from White British backgrounds made up the largest groups. There is still work to be done to reduce the stigma attached to an examination, to educate professionals about the holistic care provided and to ultimately improve access to the service for all.

\section{G490(P) ABSTRACT WITHDRAWN}

\section{G491(P) INCREASING AWARENESS OF MODERN SLAVERY AMONG HEALTHCARE PROFESSIONALS}

R Allam. Bristol Medical School, University Of Bristol, Bristol, UK

\subsection{6/archdischild-2020-rcpch.420}

Aims Modern slavery encompasses slavery, servitude, forced and compulsory labour and human trafficking. In 2017, there were 6,837 potential victims in the UK; around $31 \%(2,121)$ were children. From March 2017 to 2018, police in England and Wales recorded 3,337 modern slavery offences, a 49\% increase compared to the previous year. One in five victims encountered healthcare services during the time they were being trafficked, yet many healthcare professionals know little about modern slavery. My research aims to identify the extent of these gaps in the training of healthcare professionals.

Methods A literature review was conducted using the search terms, 'modern slavery' OR 'human trafficking' AND 'healthcare'.

Results 303 papers were identified in Pubmed, 36 in Ovid. The search was then refined with: 'humans', 'full text' and 'English language', which identified 240 papers. 15 papers were selected with relevant title and abstract, focusing on the healthcare professional's role in identifying victims of modern slavery. A cross-sectional study found that although $91 \%$ $(n=697)$ of healthcare professionals agreed that they have a responsibility to respond to suspected cases of human 
trafficking, $87 \%$ did not know how to identify these victims and $78 \%$ thought they had not received sufficient training to deal with such situations. Within medical education, $72 \%$ of UK medical schools did not provide any teaching on the subject and $70 \%$ had no plans to implement this teaching. These results overwhelmingly highlight the gap in medical education and suggest that healthcare workers would like more training on human trafficking, including the management of suspected cases.

Conclusion Overall, my research has highlighted the limited knowledge of healthcare professionals and the need for increased teaching on modern slavery to improve confidence among the healthcare community in identifying victims and reporting concerns. I would like to continue to raise awareness during my medical career and I believe that training on modern slavery should be mandatory for all healthcare professionals. Further to this, I have had a meeting with tutors from my medical school to ensure that teaching on this subject is added to the undergraduate curriculum.

\section{G492(P) ABSTRACT WITHDRAWN}

\section{G493(P) ABSTRACT WITHDRAWN}

\section{G494(P) EVALUATION OF EFFICACY AND QUALITY OF CHILD PROTECTION PEER REVIEW}

1) Slater, ${ }^{2} \mathrm{~S}$ Wong, ${ }^{1} \mathrm{~V}$ Walker. ${ }^{1}$ Community Paediatrics, Sherwood Forest NHS FT, Mansfield, UK; ${ }^{2}$ Medical School, University of Nottingham, Nottingham, UK

\subsection{6/archdischild-2020-rcpch.421}

Aim Peer review should be an established part of child protection practice in Trusts. There is guidance from the $\mathrm{RCPCH}$ and CPSIG. We undertook a service evaluation at a district general hospital using different data collection methods to evaluate quality and efficacy of the child protection medical (CPM) peer review process to ensure consistency and quality within the service.

Method 6 months of data from 01/07/2018 to 31/12/2018 were reviewed including cases via social care referral and ward admission, and data collected regarding:

- Timeliness of peer review discussion

- Outcomes e.g. communication with social care, change to report

- Perception of peer review and quality was also reviewed via a questionnaire to attendees

Results

\begin{tabular}{ll}
\hline Total Cases & 59 \\
\hline Average number discussed at meeting & 6 \\
Average number held for next meeting & 4 \\
Average time between CPM and peer review & 6 weeks \\
Average number of cases that required specific outcome & 1 per meeting \\
\hline
\end{tabular}

The questionnaire identified a positive perception of peer review; it was helpful and supported learning. Attendance was an issue due to clinical work pressures. Whilst most felt supported, there was still some anxiety about being critiqued in front of colleagues.

Conclusion Timeliness was an issue for discussion of CPM's. A case is not discussed if the consultant is not present and we suggested a nominated colleague feedback on their behalf. Acute cases were not always added for discussion. Dedicated admin, clear processes and support from the Named Doctor to appropriately run peer review is required.

Peer review runs monthly, requiring 10 case discussions per meeting; current time of 60 minutes may need to increase but an efficiently run meeting is also vital.

Dedicated time should be discussed as a team job planning priority.

A small number of cases required further liaison but no significant concerns, which is a positive reflection of the quality and consistency of the CPM's.

Child protection is recognised as a difficult area needing additional support and continued learning opportunities. Peer review of CPM's should provide this in a safe learning environment, acknowledging it does not replace supervision or evidence based courses and resources.

\section{G495(P) CHILD SEXUAL ABUSE ASSESSMENTS: HOW WELL DO WE ASSESS MENTAL HEALTH RISK AND CAPTURE ADVERSE CHILDHOOD EXPERIENCES?}

RL Stephenson, L Teebay, L Willets. Community Paediatrics and Safeguarding, Alder Hey NHS FT, Liverpool, UK

10.1136/archdischild-2020-rcpch.422

Aims

- To demonstrate identification and response to mental health issues in CYP (children and young people) who attend for sexual abuse assessments.

- To assess if information on ACEs (Adverse childhood experience) in this vulnerable population is collated.

The outcome of the study will inform discussion regarding the clinician's role in addressing mental health and resilience factors for CYP.

Methods A retrospective review of 44 patient notes of cases seen January and June 2019 at the paediatric SARC (Sexual assault referral centre) based in an NHS setting. Data was collected on patient demographics, mental health issues, actions made and documentation of ACEs/resilience factors.

Results The majority, 93\% n 41/44 of cases were female. Only $4(9 \%)$ children had a documented mental health risk assessment. $22(50 \%)$ were currently or previously known to social care prior to the assault and of these $22,9(40 \%)$ had mental health issues prior to the assault.

Conclusion A significant proportion of children and young people who access our SARC experience mental health issues and have a background of additional vulnerability and trauma.

There is referral for specialist psychological assessment through the in house paediatric SARC clinical psychology service. Paediatricians identify mental health issues and risk, but this could be improved with training and standardised guidance. 